\section{The effect of food deprivation and imprinting on the behavior of young domestic chicks*}

\author{
PAUL T. P. WONG and ABRAM AMSEL \\ University of Texas at Austin, Austin, Tex. 78712
}

The effect of food deprivation on runway performance was studied in two experiments using young domestic chicks as Ss. Considering both experiments, about $80 \%$ of the deprived chicks emitted pecking-feeding responses and ran vigorously in a runway for food, while none of the ad lib controls did. This finding was taken as evidence of a well-developed food incentive system in chicks in their second week of ontogeny.

In order to test hypotheses relating persistence to the kinds of approach responses observed in experiments on imprinting, we have been interested in running young domestic chicks under food-incentive conditions in a runway. It has been reported that food deprivation (up to $10 \mathrm{~h}$ ) has little or no increasing effect on the tendency of young chicks to approach, peck, or eat mealworm (Hogan, 1965, 1966). The implication seems to be that the behavior of young chicks cannot be understood adequately in terms of traditional drives such as hunger and thirst because, as Hogan says, "a hunger system which integrates external stimuli, pecking and food deprivation is not well developed until at least several weeks of age [p. 92]." This conclusion does not seem justified in the light of other recent experiments (Lakatos, Stoltz, \& Moyer, 1966; Marley \& Morse, 1966). Lakatos et al found that food-deprived 7-day-old chicks preferred the food-baited arm of a T-maze, while water-deprived chicks chose the water-baited alternative. Marley and Morse reported that isolated chicks up to 5 or more days old could be conditioned to peck a key for food reinforcement only when a mirror was installed in the test box. However, in neither study were ad lib controls used. Therefore, the reinforcing effect could be attributed, at least partly, to some innate tendency to peck at the food object.

The present experiments included ad lib controls, and goal approach behavior was tested in a runway. In the first experiment, both deprived and ad lib controls were put directly on a procedure of runway training with consistent food reward. In the second experiment the runway training was preceded by early training

* Supported by Grant GB-3772 from the National Science Foundation and APA-72 from the National Research Council of Canada. These experiments were performed at the University of Toronto. to approach a flickering-light stimulus of the sort described by James (1959) and others (e.g., Strobel, Clark, \& Macdonald, 1968.)

\section{SUBJECTS}

In each of the two experiments, the Ss were 16 Cornish $\mathrm{x}$ White Rock chicks hatched in the laboratory. They were removed from the incubator when they were between 6 and $16 \mathrm{~h}$ old. They were housed in individual brooder compartments, illuminated constantly by a fluorescent light, and maintained at a temperature of about $92^{\circ} \mathrm{F}$.

\section{APPARATUS}

The chick runway, made of plywood, was $45 \mathrm{in}$. long, 6 in. wide, and the height was adjustable to accommodate the growing chick. The runway was painted flat black and covered with a clear Plexiglas lid. The floor was $1 / 4$ in. hardware-cloth mesh. Two guillotine doors were used to separate out a 6 -in.-long startbox and a 1-ft-long goal compartment. Three photocells and one microswitch, connected to timers, provided time measures over three 1 -ft segments. The raising of the startdoor activated the first clock, while the breaking of the last photobeam stopped the third clock. A $2^{1 / 2} \times 1 \times 1$ in. foodcup, 3 in. from the last photobeam, was hidden behind a metal end plate which had a $2 \times 2$ in. aperture to permit access to food. The entire runway was placed in a sound-treated box with an exhaust fan. A clear Plexiglas window on the top of the box permitted observation the box was illuminated by a shaded nightlight attached to the outside of the goalbox end plate about 1 in. above the foodcup.

The imprinting apparatus was similar to that described by James (1959). It was a $6 \times 1 \times 1 \mathrm{ft}$ wooden alley painted flat black with an open top. The visual stimulus consisted of a light flickering at a rate of $.5 \mathrm{sec}$ on of the chick's behavior. The interior of and .5 sec off through four holes, $3 / 4$ in. in diam and arranged in a diamond pattern. An auditory stimulus, synchronous with the flicker, was emitted at the same end of the alley as the light stimulus by a small PM speaker at about $75 \mathrm{~dB}$.

\section{PROCEDURE}

Imprinting

On Days 1-5, chicks in Experiment 1 were left in the brooder untouched, but in Experiment 2 each chick was given two 5-min imprinting sessions per day. On each trial the imprinting order for the 16 chicks was randomized. The imprinting procedure was conducted in a dark room with an exhaust fan on all the time. The only source of illumination was a shaded $7 \cdot \mathrm{W}$ bulb to enable the $\mathrm{E}$ to record data.

\section{Food Deprivation}

In both experiments, chicks were assigned randomly to one of the two conditions, deprived or ad lib. Locally prepared starter krums and water were made available in abundance on the second day posthatch in individual home cages. On Day 5, foodcups were removed from the deprived birds, which were maintained on the following deprivation schedule from then on: Days 6-7, $20 \mathrm{~h}$; Days 8-9, $22 \mathrm{~h}$; Days 10 to the end of experiment, $23 \mathrm{~h}$. Each day, deprived birds received their daily ration of food only after all Ss had completed their test trials. The ad lib controls had free access to food throughout the experiment.

\section{Goalbox Feeding}

On Day 7, four pairs of chicks were formed randomly from the eight $S$ s in each condition, and each pair was placed in the baited goalbox for $10 \mathrm{~min}$. The foodcup was filled with starter krums and illuminated by a nightlight. This goalbox placement procedure was repeated on Day 8 with the same pairs of birds. On Day 9, chicks were placed in the goalbox one at a time and allowed only $30 \mathrm{sec}$ of feeding. Birds that did not eat immediately were confined in the goal compartment for up to $10 \mathrm{~min}$.

Runway Training

On each runway trial a chick was placed in the startbox, and about 2 sec later the startdoor was raised. A maximum of $3 \mathrm{~min}$ was allowed for each trial, and, if a chick failed to reach the last photobeam within this time, it was removed and placed in the goalbox. Reward was $30 \mathrm{sec}$ of feeding in a maximum allowable time of $60 \mathrm{sec}$ in the goalbox.

On the first 2 days of runway training, there were two trials per day; on the third day, four trials; on the last 3 days, eight trials. The minimum intertrial interval was $25 \mathrm{~min}$. Running order was randomized on each day. 


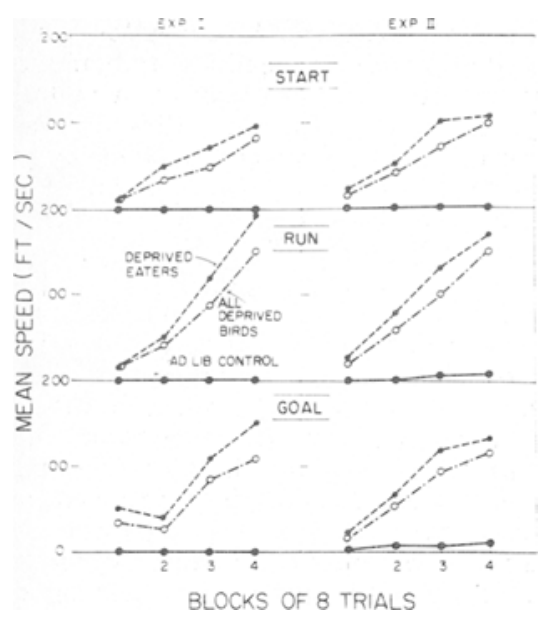

Fig. 1. Speed data from both experiments showing comparisons with ad lib controls for all deprived Ss (deprived birds) and for only those deprived Ss which ate in the goalbox feeding phase (deprived eaters).

RESULTS AND DISCUSSION

Since both experiments had identical procedures, except for the imprinting phase in the second, the results of the two experiments are presented and discussed together.

\section{Imprinting}

A bird was considered to have imprinted if it approached to within $1 \mathrm{ft}$ of the imprinting stimulus within $5 \mathrm{~min}$. By the fourth trial, all 16 chicks in Experiment 2 were imprinted.

Pecking and Feeding Behavior

On the first trial (Day 7), all eight pairs of chicks in Experiment 1 sat through the $10-\mathrm{min}$ period without any noticeable movement or utterance of calls. This total suppression of activity was probably due to intense fear induced by the novel environment (Candland, Nagy, \& Conklyn, 1963 Hogan, 1965, 1966; Saltzen, 1962). However, in Experiment 2 one in each pair of the deprived birds pecked at the food and ate briefly. There was no indication of any aggressive behavior to establish a pecking order. While one bird was eating, its partner simply walked around peeping or sat quietly preening. Generally, birds in Experiment 2 were more active. This could be due to prior imprinting experience and handling. By the third trial (Day 9), all but four of the deprived birds, two in each experiment, pecked and ate. Their feeding behavior became more vigorous and less interrupted by pauses and bouts on this last trial. None of the ad lib birds pecked at the food throughout the three feeding trials, despite the use of the social facilitation technique (Zajonc, 1965; Tolman \& Wilson, 1965).

Acquisition of Running

Time scores were transformed into speeds (ft/sec), and mean speed data for both experiments are shown in Fig. 1. Acquisition curves for eaters in the deprived groups and for all birds in the deprived groups are plotted separately.

In both experiments, every deprived eater was running vigorously (a minimum alley speed of $1 \mathrm{ft} / \mathrm{sec}$ ) during the last 2 days of runway training, while none of the ad lib controls and noneaters were. Some of the eaters pecked vigorously at the guillotine door as soon as they were placed inside the startbox, which can be taken as indicative of an anticipatory goal response elicited by cues of the startbox, i.e., of a food incentive system.

None of the ad lib controls emitted pecking or feeding responses. In Experiment 1, none of the controls ever moved out of the startbox throughout the 32 acquisition trials. They simply sat through the 3-min period, and the same "freezing" behavior was observed when they were placed in the goalbox. In Experiment 2, there was some suggestion of transfer of approach behavior from the light-sound imprinting stimulus to the light over the foodcup in the goalbox, in that two of the eight ad lib birds approached the illuminated goalbox consistently; but their speed never exceeded $.5 \mathrm{ft} / \mathrm{sec}$. The other ad lib controls of Experiment 2 behaved just like those in Experiment 1, i.e., they sat through every trial both in the start- and goalboxes.

Considering both experiments, the deprived noneaters seemed more active than the ad lib controls. Three noneaters moved out of the startbox once within $60 \mathrm{sec}$. Two of these birds entered the goalbox once. However, these three noneaters never pecked at the food. 1

Although there is evidence that pecking at three-dimensional, especially grain-shaped objects is an innate behavior in domestic chicks (Fantz, 1961), only food-deprived chicks in the present experiments emitted pecking reponses, even to food.
The instrumental running response was acquired only by the deprived birds which had previously eaten in the goal region, and this can be accounted for only in terms of the operation of a food-incentive system. Because there may be confusion on this point, we would like to stress that by "food-incentive system" we do not mean simply pecking at and eating food visible to the hungry bird; we are referring to the activation of instrumental responding by cues signaling food and not by food itself.

\section{REFERENCES}

CANDLAND, D. K., NAGY, Z. M., \& CONKLYN, D. H. Emotional behavior in the domestic chicken (white Leghorn) as a function of age and developmental environment. Journal of Comparative \& Physiological Psychology, 1963, 56. 1069-1073.

FANTZ, R, L. The origin of perception. Scientific American 1961, 204, 66-72.

HOGAN, J A. An experimental study of conflict and fear: An analysis of behavior of young chicks toward a mealworm. Part I. The behavior of chicks which do not eat the mealworm. Behaviour, 1965 , $25,45-97$.

HOGAN, J. A. An experimental study of conflict and fear: An analysis of behavior of young chicks toward a mealworm. Part II: The behavior of chicks which eat the mealworm. Behaviour, 1966, 27, 272-289.

JAMES, H. Flicker: An unconditioned stimulus for imprinting. Canadian Journal of Psychology, 1959, 13, 59-67.

LAKATOS, R. J., STOLZ, C, \& MOYER, R. S. Effects of deprivation procedures on consummatory motivation in the domestic chicken Journal of Genetic Psychology, 1966, 109, 231-239.

MARLEY, E., \& MORSE, W. H. Operant conditioning in the newly hatched chicken. Journal of the Experimental Analysis of Behavior, 1966, 9, 95-103.

SALTZEN, E. A Imprinting and fear. Zoological Society of London Symposia. $1962,8,199-217$

STROBEL, M. G., CLARK, G. M., \& MacDONALD, G. E. Ontogeny of the approach response: A radiosensitive period during embryological development of domestic chicks. Journal of Comparative \& Physiological Psychology. $1968,65,314-319$

TOLMAN, C. W. \& WILSON, G. T. Social feeding in domestic chicks. Animal Behaviour, $1965,13,134$.

ZAJONC, R. B. Social facilitation. Science, $1965,149,269-274$.

1. Based on all the experiments run in our laboratory using domestic chicks as $\mathrm{Ss}$, an average of about one out of every five deprived birds is a noneater. Some of these chicks failed to eat in the goalbox despite several hours of exposure to the runway situation. Generally, the noneaters displayed more emotional behavior such as "freezing" or shrill calling than the eaters. 